\title{
The Super Justification Argument for Phenomenal Transparency
}

\author{
Penultimate draft; forthcoming in Inquiry (online first here)
}

\begin{abstract}
In Consciousness and Fundamental Reality, Philip Goff argues that the case against physicalist views of consciousness turns on "Phenomenal Transparency", roughly the thesis that phenomenal concepts reveal the essential nature of phenomenal properties. This paper considers the argument that Goff offers for Phenomenal Transparency. The key premise is that our introspective judgments about current conscious experience are "Super Justified", in that these judgments enjoy an epistemic status comparable to that of simple mathematical judgments, and a better epistemic status than run of the mill perceptual judgments. After presenting the key ideas in the "Super Justification Argument", I distinguish two Super Justification theses, which vary according to the kind of introspective judgments that they take to be Super Justified. I argue that Goff's case requires "Strong Super Justification", according to which a wide range of introspective judgments about conscious experience are Super Justified. Unfortunately, it turns out that Strong Super Justification is implausible and not well-supported by examples. In contrast, a weaker Super Justification thesis does not require anything like Phenomenal Transparency and, indeed, can be explained by physicalistic accounts of phenomenal concepts.
\end{abstract}

Keywords: phenomenal concepts, introspection, phenomenal properties, consciousness

\section{Introduction}

A case can be made that familiar arguments against physicalism about consciousness are successful only if we are in an especially strong epistemic position with respect to the nature of conscious experience. Indeed, arguments for this kind of thesis have been pursued both by physicalists (who argue that we are not in the requisite epistemic position) and anti-physicalists (who argue that we are in the requisite epistemic position). ${ }^{1}$ In Consciousness and Fundamental Reality, Philip Goff goes so far as to argue that the case against physicalism about consciousness turns on "Phenomenal Transparency", roughly the thesis that phenomenal concepts reveal the essential nature of phenomenal properties. Given that we can form such concepts through attending to our conscious experiences, it

\footnotetext{
${ }^{1}$ Physicalists who have endorsed this kind of position include Hill 2009 and Pereboom 2011, while anti-physicalists include Chalmers 2009 and Goff 2017. The connection between the status of physicalism and our epistemic position with respect to conscious experience is also noted in Broi forthcoming.
} 
follows that we grasp the essential nature of phenomenal properties. Goff contends that the Knowledge Argument due to Frank Jackson and the Conceivability Argument articulated in great detail by David Chalmers succeed if and only if Phenomenal Transparency is true. ${ }^{2}$ Moreover, Goff argues that if Phenomenal Transparency is true, there is a more direct case against physicalism about consciousness that bypasses, for example, considerations relating to conceivability and possibility. ${ }^{3}$

In my view, Goff and others are correct that the case against physicalism requires, and moreover is arguably successful, if we are in an especially strong epistemic position with respect to the nature of phenomenal properties. Indeed, Goff may be right that the case against physicalism succeeds if and only if Phenomenal Transparency is true. However, I believe that this is in the service of the physicalist, since I doubt that we are in the requisite epistemic position. Here I will limit myself to the modest task of considering the status of Phenomenal Transparency and, especially, the argument that Goff offers for Phenomenal Transparency. The argument has several steps, but the key premise is that our introspective judgments about current conscious experience are "Super Justified", in that these judgments enjoy an epistemic status comparable to that of simple mathematical judgments, and a better epistemic status than run of the mill perceptual judgments. Goff contends that the best explanation for our introspective judgments about conscious experience being Super Justified is "Revelation", according to which the nature of phenomenal properties is wholly captured by certain phenomenal concepts in virtue of phenomenal properties being directly presented in experience. Since Revelation entails Phenomenal Transparency, this amounts to an argument for Phenomenal Transparency.

I don't think that this argument works; nor do I think that the intuitive case for Phenomenal Transparency is as compelling as Goff supposes. After presenting the key ideas in the "Super Justification Argument", I distinguish two Super Justification theses, which vary according to the kind

\footnotetext{
${ }^{2}$ See Goff 2017, Chapters 3 and 4. For Jackson's presentation of the knowledge argument, see Jackson 1982 and 1986; for Chalmers's presentation of the conceivability argument, see Chalmers 1996 and 2009.

${ }^{3}$ See Goff 2017, Chapters 4 and 5.
} 
of introspective judgments that they take to be Super Justified. My position is that Goff's case requires "Strong Super Justification", according to which a wide range of introspective judgments about current conscious experience are Super Justified. Unfortunately, it turns out that Strong Super Justification is implausible and not well-supported by examples. In contrast, I argue that a weaker Super Justification thesis can be explained without anything like Revelation and, indeed, can be explained by physicalistic accounts of phenomenal concepts, including the "quotational" or "constitutive" model of phenomenal concepts developed by David Papineau. ${ }^{4}$ My discussions can be viewed as offering a limited defense of physicalism, given that the case against physicalism turns on whether we are in an especially strong epistemic position with respect to the nature of consciousness.

I will begin by clarifying some of the terms just introduced before turning to the Super Justification Argument for Phenomenal Transparency.

\section{The Super Justification Argument for Phenomenal Transparency}

When we have a conscious experience, we may think about that experience in terms of its phenomenal properties, what it is like to have that experience. In considering an experience in terms of what it is like to have that experience, we form "phenomenal concepts" of that type of experience. Generally, phenomenal concepts are those concepts that we employ when we think about conscious experiences in terms of what it is like to have them - in terms of how they feel, as felt sensation. Thus one may think of pain in terms of what it is like to have pain; in doing so, one employs a phenomenal concept of pain. Of course, one may also have non-phenomenal concepts of pain, and conscious experience generally, as when one thinks about pain not in terms of how it feels, but rather in terms of its causes and effects. Following Goff $(2017,107)$, we can further distinguish between "direct" and "indirect" phenomenal concepts, where a direct phenomenal concept is a concept that one forms when having the

\footnotetext{
${ }^{4}$ See Papineau 2002.
} 
very type of experience to which the concept refers, as when one thinks of an occurrent pain in terms of how that pain feels. An indirect phenomenal concept, in contrast, is a phenomenal concept that one may employ when not having the specific type of experience to which the concept refers, as when one thinks about pain in terms of what it is like to have pain when not having an experience of pain.

What does one know about a type of experience in virtue of having a phenomenal concept of that type of experience? According to Phenomenal Transparency, one knows everything essential that there is to know. Following $\operatorname{Goff}(2017,15)$, we can say that a concept $\mathrm{C}$ is transparent just in case $\mathrm{C}$ reveals the nature of the entity to which it refers, in that it is a priori (for someone possessing the concept and in virtue of possessing the concept) what it is for that entity to be part of reality. In other words, for a concept to be transparent is for it to put the concept user in a position to know, just in virtue of possessing the concept, the nature of that to which the concept applies. In this sense, nothing about what to which the concept refers is "hidden from view" to the concept user. Goff $(2017,15-16)$ considers sphericity a paradigm example of a non-phenomenal concept that is transparent in this sense - arguably, if one has the concept sphericity, one is thereby in a position to know, a priori, what it is for something to be spherical, what it is for the property being spherical to be instantiated or "part of reality". The contrast is with concepts like water, where one can possess the concept and competently apply the concept without knowing the nature of that to which the concept refers; rather, to know the nature of water requires substantive empirical investigation. While the distinction between transparent and non-transparent concepts may raise a number of questions, my concerns about the Super Justification argument for Phenomenal Transparency do not turn on general concerns about the very notion of a transparent as opposed to non-transparent or "opaque" concept.

Direct Phenomenal Transparency, the thesis that direct phenomenal concepts are transparent, is evidently entailed by what Goff calls "Revelation", the thesis that: 
In having a direct phenomenal concept, the token conscious state being attended to is directly presented to the concept user, in such a way that (i) the complete nature of the type to which it belongs is apparent to the concept user and (ii) the concept user knows with certainty (or something close to it) that the token conscious state exists (as a token of that type). $(2017,107)$

Revelation entails that direct phenomenal concepts, at least, are transparent: Revelation supposes that when one attends to a conscious state using a direct phenomenal concept, "the complete nature of the type to which it belongs" is apparent to the concept user (ibid). In other words, if Revelation is true, it follows that when we form concepts of current conscious experiences in terms of what it is like to have them, we grasp what it is for there to be an experience of that type and have near-certain knowledge that we are indeed having that type of experience. Revelation explains the transparency of direct phenomenal concepts in terms of the immediacy of current conscious experience - as Goff puts it, conditions (i) and (ii) in Revelation hold because current conscious experiences are "directly presented", "right there" for one to consider $(2017,107-8)$.

In my view, Revelation and Direct Phenomenal Transparency are intuitive but nonetheless in need of an argument. There is something intuitive to the idea that when I am having a pain, and I think about that pain in terms of what it is like, I thereby grasp something essential about pain, what it is for there to be an experience of that type, and that I know with near-certainty that I am having an experience of that type. However, intuitive or not, Revelation and Direct Phenomenal Transparency are strong philosophical claims. They are claims that many smart, well-read philosophers have denied. Many philosophers, for example, have argued that phenomenal concepts are more like blind pointers to experiences that reveal little or nothing about the nature of the states to which they refer. ${ }^{5}$ Indeed,

\footnotetext{
${ }^{5}$ As suggested in Loar 1997, McLaughlin 2001, and Papineau 2002.
} 
some have argued that phenomenal concepts, or something like them, are positively misleading, in that they represent consciousness as having properties that it in fact does not possess. ${ }^{6}$ Likewise, when considering examples other than pain, Revelation is not quite as intuitively compelling. ${ }^{7}$ Take a complex visual scene, such as an intricate mandala painting or a classic Monet. In examples like this, it is really not intuitively obvious that merely by attending to my experience, "the complete nature" of the type of visual experience to which my current visual experience belongs is apparent. Similarly, when considering a three second chunk of auditory experience, such as a three second chunk of Beethoven's ninth, it is just not intuitively obvious that there is real sense in which, simply in virtue of attending to that experience, I thereby grasp the essence of that type of auditory experience. Moreover, Revelation prima facie comports poorly with the idea that there may be phenomenal aspects of experience that, despite one's considered attention, may remain hidden, as one may notice a new phenomenal aspect of a song that one has heard many times, or as one may finally taste the cherry in the wine that one has been drinking for many years. How could this be if, as Revelation supposes, my current conscious experiences are "right there" for me, with "nothing in any way hidden"?

I do not intend any of this as a refutation of Revelation or Direct Phenomenal Transparency, and I am aware that there are ways in which one might try to show that these apparent facts about experience are consistent with Revelation and Direct Phenomenal Transparency. For example, in response to the wine-tasting example, one may claim that the phenomenal elements that one discerns at a later point were simply absent at the earlier point of time - that, perhaps with certain training, genuinely new phenomenal elements appear within one's total conscious experience. But I do think that these considerations raise concerns about the intuitiveness of Revelation and Direct Phenomenal

\footnotetext{
${ }^{6}$ As suggested in Frankish 2016, Hill 2009, and Pereboom 2011.

${ }^{7}$ While I have conceded that Phenomenal Transparency is intuitive in the case of pain, this might also be disputed. Thus in some meditative experiences, when introspecting on a particular pain, the feeling itself often seems elusive, as if it has aspects that are in a sense hidden from view.
} 
Transparency. They suggest, perhaps, that the intuitiveness of these theses might be the result of a sampling error.

For his part, despite suggesting $(2017,108)$ that one might take Revelation as "bedrock", Goff recognizes the dialectical need for an argument. The argument that he offers is an inference to the best explanation. Specifically, he claims that Revelation is the best explanation for "Super Justification", the thesis that our introspective judgments about current experience are epistemically superior to perceptual judgments about the external world and are rather epistemically on a par with basic mathematical judgments, such as the judgment that $1+1=2(2017,110-11)$. Goff's case for Super Justification is essentially Cartesian, premised on the epistemic possibility of radical error about the external world. In this context, he puts forward the following example (ibid). Suppose you are in an art gallery and come upon a painting that consists of a uniformly orange splodge on the left and a uniformly red splodge on the right. Now consider the perceptual judgment that the splodge on the right side of the painting resembles the splodge on the left side, along with the introspective judgment that the experience of the splodge on the right side of the painting resembles the experience of the splodge on the left side. Which is more epistemically secure? According to Goff, the possibility of skeptical scenarios imply that it is the latter. After all, even if some skeptical scenario obtains, "it's hard to dissuade myself of the evident truth that what it's like for me to experience that - the left-hand splodge - is similar to what it's like for me to experience that - the right-hand splodge" $(2017,110)$. Given this, Goff submits

that many of our introspective judgments about our conscious experience are such that the degree of confidence we are entitled to hold in them is roughly the same as the degree of confidence we are entitled to hold in our basic mathematical judgments... I will express this claim by saying that certain introspective judgments are "superjustified.” $(2017,111)$ 
But what explains Super Justification - what explains the fact that our introspective judgments enjoy this especially strong epistemic status? Goff claims that Revelation provides the best explanation:

Return to the experience of red and orange splodges. According to Revelation, when I attend to the token conscious state representing the red and orange splodges, that state is directly presented to me...In grasping the nature of each aspect of the experience...I grasp that they have similar natures. And given that I have great rational confidence in the reality of each aspect, each having the nature that is directly presented to me, I thereby know with an extremely high degree of rational confidence that they resemble. $(2017,112-13)$.

In contrast, he argues that physicalist accounts of phenomenal concepts cannot explain Super Justification. Thus consider the "constitutive" or "quotational" account of phenomenal concepts due to Papineau. According to this account, phenomenal concepts (or at least direct phenomenal concepts) "refer to phenomenal qualities virtue of being partly constituted by those qualities" $(2017,115)$. This account has been put forward by physicalists in an attempt to explain away dualist intuitions. Goff argues, however, that it cannot explain Super Justification, essentially because it cannot explain why resemblance judgments like the one above are Super Justified. This is because, according to Goff, the quotational account can only deal with introspective judgments of the form "I am currently having this experience", where a direct phenomenal concept is used to pick out the experience in question, and cannot moreover explain the strong epistemic credentials of resemblance judgments either across experiences or within an experience $(2017,116)$. The result is that Revelation is needed to explain Super Justification. But Revelation entails Direct Phenomenal Transparency.

\section{Against Strong Super Justification}


It is not an accident that Goff appeals to resemblance judgments in arguing for Super Justification. After all, it is precisely the strong epistemic credentials of these sort of judgments that, he contends, certain physicalist accounts of phenomenal concepts cannot explain. However, his use of introspective resemblance judgments raises a number of questions and, I believe, ultimately undermines the case for Revelation.

First, while I will not pursue the concern in detail, it could be maintained that the epistemic credentials of the introspective judgment involved in the red and orange splodges example can be wellexplained without supposing that we have anything like a grasp of the nature of conscious experience. Specifically, one might reason that the experience of the red splodge exists, the experience of the orange splodge exists, and everything resembles everything else in some respect or other; hence, these experiences resemble. Perhaps the judgment about the existence of the relevant experiences involves introspection, but it is not clear how the epistemic credentials of this judgment should turn on whether one grasps the nature of the experiences. After all, the epistemic credentials of existence claims do not generally turn on whether one grasps the very nature of that which is judged to exist. And in the present case, the Cartesian proposal that we cannot doubt the existence of the relevant experiences does not suppose a grasp of the nature of that which it judged to exist. Indeed, it is worth recalling that Descartes himself supposed that even upon securing the certain existence of his self, the question of the nature of this self required further discussion.

In any case, I will not pursue this worry further. I will assume that Goff has in mind what might be referred as "substantive resemblance judgments", judgments about resemblance that go beyond the fact that everything resembles everything else in some respect. This, of course, requires some account of a substantive resemblance judgment, and I do not have any such account to offer. It is also worth marking that as I understand the dialectic, the case for the strong epistemic credentials of introspective judgments about current experience is not supposed to turn on any substantive account of the nature of 
resemblance. Rather, it is supposed to be evident to introspection, and supported by broadly Cartesian considerations, that such judgments are Super Justified. ${ }^{8}$

Second, and more importantly, it is possible to distinguish at least two Super Justification theses, depending on what sort of introspective judgments about current experience are taken to be Super Justified. Consider the following kinds of introspective judgments:

1. I am having an experience now.

2. I am having that kind of experience now.

3. That experience now resembles that experience now.

As I understand Goff's position, it is that introspective judgments in each of these categories are in a better epistemic position than perceptual judgments and are epistemically akin to simple mathematical judgments. But one could hold weaker theses. For instance, one might hold (as I think is plausible) that introspective judgments of the sort (1) and (2) enjoy something like Super Justification, but deny that this also holds when one includes judgments of the sort (3). I will refer to the position that Super Justification holds for introspective judgments in all of these categories as "Strong Super Justification", while I will refer to the position that Super Justification only holds for introspective judgments of the sort (1) and (2) as "Weak Super Justification".

It is time for me to put my cards on the table. I believe that Weak Super Justification is plausible, but does not require Revelation as an explanation. Indeed, I believe that Revelation is in fact in tension with this weaker thesis. I am willing to concede that Revelation explains Strong Super Justification, and perhaps a better explanation than the alternatives. However, Strong Super Justification is not itself especially plausible.

\footnotetext{
${ }^{8}$ See below for further remarks on the metaphysics of resemblance and the epistemic credentials of introspective resemblance judgments.
} 
Before presenting my case against Strong Super Justification, it is important to introduce a distinction between two varieties of resemblance. ${ }^{9}$ First, when considering whether two items resemble, or whether one item resembles another more than it resembles some other item, one may have in mind a notion of overall resemblance. In this case, one considers the myriad similarities and differences that the items exhibit and, on this basis, forms a judgment as to whether, all things considered, the items resemble or whether, all things considered, one item resembles another more than it resembles some other item. For example, one may ask whether, all things considered, a particular apple resembles a particular orange more than it resembles a particular banana. Second, when considering whether two items resemble, or whether one item resembles another more than it resembles some other item, one may have in mind a notion of respective resemblance. In this case, one considers whether the items resemble in some particular respect, as one may consider whether two items are similar with respect to shape, or as one may consider whether one item resembles another more than it resembles some other item with respect to color. Finally, to introduce an issue that will recur, overall resemblance judgments raise issues that prima facie do not arise for respective resemblance judgments. In particular, overall resemblance would seem to involve some kind of aggregation of respective resemblances and differences. However, it is a matter of dispute how such aggregation should proceed or whether such aggregation is even possible. ${ }^{10}$

Regarding Goff's example of the introspective judgment that the splodge on the right side of the painting resembles the splodge on the left side, should this be understood as a judgment of overall resemblance or as a judgment of respective resemblance? I think that it can be interpreted either way. On the one hand, when presenting the example, Goff seems to understand it as a judgment of overall

\footnotetext{
${ }^{9}$ For useful discussion of the distinction of interest, see Cowling 2017. I am grateful to an anonymous referee at Inquiry for pressing the need for this distinction in the present context.

${ }^{10}$ For skepticism about the idea that overall resemblance can understood as the aggregation of respective resemblance and difference relations, see Morreau 2010.
} 
resemblance. After all, in presenting the example, Goff never qualifies the judgment as concerning resemblance in any particular respect. On the other hand, the example can be understood as a judgment of respective resemblance, namely as the judgment that the experience of the red splodge resembles the experience of the orange splodge with respect to color. However, a case can be made that either option is problematic, since when considering various other examples, it seems that neither introspective judgments concerning overall resemblance nor introspective judgments concerning respective resemblance are Super Justified.

Consider, then, the judgment involved in the splodges example, and suppose that this is interpreted as judgment of overall resemblance. It obviously does not follow from the fact that this judgment is epistemically well-grounded that introspective judgments of overall resemblance in general are epistemically well-grounded, and better grounded than ordinary perceptual judgments. And I believe that reflection on cases suggests otherwise. Consider, for example, the introspective judgment that an occurrent auditory experience of a $\mathrm{C}$ note plucked on the third fret of the A string on a guitar resembles an occurrent auditory experience of a $\mathrm{G}$ note plucked on the third fret of the low E string. When considering examples like this, rather than deliver any definite verdict, introspection seems to leave me in the dark. I certainly do not feel as confident in this judgment as in the ordinary perceptual judgment that there is a beer bottle on the table in front of me. The same seems to be true of related three-place overall resemblance judgments. All things considered, is an occurrent experience of a C3 on a guitar more similar to an occurrent experience of a $\mathrm{C} 4$, in virtue of the two both being $\mathrm{Cs}$ (though an octave apart), or is an occurrent experience of a $\mathrm{C} 3$ more similar to an occurrent experience of a B3, since the two are closer in pitch? Does an experience of a $\mathrm{G}$ on a guitar more closely resemble an experience of a $\mathrm{C}$ on a guitar, or an experience of a $\mathrm{G}$ on a piano? When I introspectively consider the relevant experiences, I am at something of a loss as to what to say about these examples; when I consider the relevant experiences, I am left with befuddlement rather than confidence. My confidence 
in the basic deliverances of perception seems more secure than my confidence when it comes to these introspective judgments, and it is difficult to conceive of how the latter might have an epistemic status comparable to that of simple mathematical judgments. ${ }^{11}$

It is important to note that I do not deny that these questions about resemblance relations among occurrent experiences may admit of principled answers. To more or less say the same thing, my aim is not to raise general concerns about overall resemblance and judgments about overall resemblance. Regarding the examples just sketched, one may, for example, distinguish different aspects for comparison, assign different weights to them, and thereby conclude, for example, that a $\mathrm{G}$ on a guitar more closely resembles a $\mathrm{C}$ on a guitar than a $\mathrm{G}$ on a piano. Setting aside general skepticism about overall resemblance - an issue to which I will return - I see no reason why this cannot be done in the examples just sketched. However, while I am willing to concede that definite verdicts may be available, I doubt that they will come from introspective comparisons of occurrent experiences. In this respect, I believe that our overall resemblance judgments about "external" properties may well be in a better epistemic position than our introspective judgments about occurrent experience, as the former but not the latter may make use of substantive criteria for evaluating relations of resemblance and similarity. In the examples concerning occurrent auditory experience, the most plausible position seems to be captured in the conditional statement, according to which if there are facts about overall resemblance in these cases, introspection leaves us in the dark when it comes to knowing these facts, and does not seem to deliver results that are epistemically superior to run of the mill perceptual judgments and epistemically on a par with simple mathematical judgments.

When it comes to introspective judgments of overall resemblance, it is not difficult to multiply examples in which it seems wrong to take the judgments to be Super Justified. For example, consider

\footnotetext{
${ }^{11} \mathrm{I}$ am indebted to $\mathrm{X}$ for some of the examples in this paragraph.
} 
the introspective judgment that, all things considered, an occurrent tactile experience of tickle resembles an occurrent experience of mild pain. If asked how confident I should be in this judgment, I am at something of a loss; I certainly do not think that I should be more confident in this judgment than in an ordinary perceptual judgment about the surrounding environment. All things considered, does the phenomenal character of my dull headache more resemble the dull itch in my right armpit than it resembles the sharp pain in my left toe? All things considered, does the sharp pain in my left toe more resemble the profound itch in my left arm pit than it resembles the dull pain in my lower back?

Again, I do not deny that questions like these can be answered. But such answers are not evident to introspection. Introspectively, it is really unclear what one ought to say in response to these sort of questions, and it does not seem that the answers to them are more epistemically secure than the answers to questions about the immediate external environment. But in this case, we have reason to doubt that introspective judgments of overall resemblance across occurrent experiences are Super Justified - we have reason to believe that if any introspective judgments about current conscious experience have stronger epistemic credentials than ordinary perceptual judgments, introspective judgments about overall resemblance relations between experiences are not among them.

It might be suggested that in the auditory and tactile examples, there is simply no fact of the matter concerning overall resemblance - for example, that there is just no fact of the matter concerning whether, all things considered, an experience of a $\mathrm{G}$ on a guitar more closely resembles an experience of a $\mathrm{C}$ on a guitar than an experience of a $\mathrm{G}$ on a piano or whether, all things considered, the phenomenal character of my dull headache more resembles the dull itch in my right armpit than it resembles the sharp pain in my left toe. ${ }^{12}$ In this case, one could hardly blame introspection for failing

\footnotetext{
${ }^{12}$ I am grateful to an anonymous referee at Inquiry for pressing this concern.
} 
to deliver a definite verdict on these and related examples. However, while I am not entirely unsympathetic to this concern, I think that it is ineffective against the present criticism of Super Justification about introspective judgments of overall resemblance. For one thing, from a dialectical perspective, on the present interpretation of Goff's splodges examples, according to which this is a judgment about overall resemblance, general skepticism about overall resemblance is not an option if overall resemblance is in general problematic, this undermines the force of the initial splodges example, if indeed the example is supposed to concern overall resemblance. Given this, the present line of response would need to maintain that while there is a fact of the matter concerning overall resemblance in the splodges example, there is no fact of the matter concerning overall resemblance in the auditory and tactile examples. However, it is difficult to see how there could be a principled basis for such a distinction - how it could be maintained that while overall resemblance across auditory and tactile experiences is problematic, overall resemblance across visual experiences is not. In other words, if there are facts about overall resemblance across visual experiences, which the splodges example requires on the present interpretation, I do not see why there should not also be facts about overall resemblance across auditory experiences or tactile experiences.

What if the splodges example is interpreted as an introspective judgment of respective resemblance, perhaps as the judgment that the experiences of the splodges resemblance with respect to color? Could it be maintained that even if introspective judgments of overall resemblance are not Super Justified, introspective judgments of respective resemblance nonetheless enjoy this strong epistemic status? For example, even if introspection leaves us in the dark as to whether, all things considered, an experience of a $\mathrm{G}$ note resembles an experience of an $\mathrm{F}$ note more than an experience of a E note, perhaps the introspective judgment that an experience of a $\mathrm{G}$ resembles an experience of an $\mathrm{F}$ more than an experience of an $\mathrm{E}$ with respect to pitch may nonetheless be Super Justified. Likewise, even if introspection leaves me in the dark as to whether, all things considered, the 
phenomenal character of my dull headache more resembles the dull itch in my right armpit than it resembles the sharp pain in my left toe, perhaps the judgment that the phenomenal character of my dull headache more resembles the dull itch in my right armpit than it resembles the sharp pain in my left toe with respect to intensity may nonetheless be Super Justified.

Unfortunately, while the claim that introspective judgments of respective resemblance are Super Justified is less implausible than the corresponding claim about judgments of overall resemblance, it falls short of being compelling. Consider, first, the auditory case. The first thing to note is that to have any chance of making reliable judgments about pitch, one needs a substantive conceptual and theoretical background. Second, it is important to recall that the issue is not just whether we can make reliable introspective judgments; it is rather whether such judgments have an epistemic status of near certainty, a status superior to ordinary perceptual judgments and more akin to simple mathematical judgments. It is this latter claim that seems doubtful, even when considering introspective judgments of respective resemblance. With appropriate training and conceptual competence, it is plausible that one can be reasonably confident in such judgments, as one may be confident in the judgment that an experience of a $\mathrm{G}$ resembles an experience of an $\mathrm{F}$ more than an experience of an $\mathrm{E}$ with respect pitch. But what I am not willing to concede is that this verdict approaches anything like rational certainty, or that we should be more confident in this verdict than in basic perceptual judgments. The possibility of error seems as least as inherent in the introspective judgment as in any typical perceptual judgment.

The same seems true in the tactile case. I am willing to concede that in many cases, one can form reliable introspective judgments as to whether certain tactile experiences more or less resemble with respect to intensity. I certainly do not wish to deny, for example, that the introspective judgment my dull headache more resembles the dull itch in my right armpit than it resembles the sharp pain in my left toe with respect to intensity may be well-justified. But what does not seem correct is to suppose that such judgments typically enjoy something approaching rational certainty, or that such judgments 
typically enjoy a more secure epistemic status than run of the mill perceptual judgments. Indeed, in many cases, such judgments seem prone to doubt and uncertainty in a way that perceptual judgments about the immediate environment are not. Consider the tactile experience in the tips of my fingers as I type these words, the dull but noticeable pain in my stomach, and the dull but noticeable pain in my head with respect to intensity. Perhaps with some reflection, I may be able to come up with a resemblance ordering among these experiences with respect to intensity. But what do I not get is the idea that this judgment should be regarded as epistemically superior, say, to the perceptual judgment that there is a there is a beer bottle on the table in front of me. Indeed, the opposite seems to be the case; it is the perceptual judgment that seems more secure and less prone to error.

Putting this together, there is reason to think that introspective judgments concerning both overall resemblance relations between occurrent experiences and respective resemblance relations between occurrent experiences fall short of being Super Justified. In many cases, it seems that the confidence that one ought to have in the deliverances of introspection fall short of anything like rational certainty and are no better off than ordinary perceptual judgments. But in this case, Strong Super Justification must be rejected.

The cases here described are in some ways reminiscent of Eric Schwitzgebel's (2008) critique of the reliability of introspection. Schwitzgebel appeals to various cases in which introspection simply fails to yield the sort of verdict that, if it were reliable, it evidently ought to yield. For example, Schwitzgebel considers whether there is a distinctive phenomenology of intentionality - whether, instance, there is something it is like to think that George Washington crossed the Delaware on Christmas Eve during some year or other, some phenomenology that goes beyond just the images that one may associate with the thought. When I introspect, I do not find any such phenomenology, but apparently others do. In any case, it should be marked that despite some superficial similarities, my aims are more modest than Schwitzgebel's. First, I have specifically called into question only the 
reliability of introspective resemblance judgments, whereas Schwitzgebel aims to call into question the general reliability of introspection. Indeed, concerning introspective judgments of respective resemblance, I am happy to accept that we are typically reliable. I simply doubt that this reliability is superior to that of typical perceptual judgments and that such introspective judgments are epistemically on a par with simple mathematical judgments. Second, my more general aim is to call into question whether introspection reveals the nature of phenomenal properties, whether direct phenomenal concepts are transparent. One might well hold that introspection, and phenomenal concepts formed on the basis of introspection, fail to reveal the essential nature of experience while nonetheless holding that introspection is typically reliable (as I tend to believe is the case).

In these ways, while my case is similar to Schwitzgebel's in certain respects, it is rather more modest. Moreover, certain responses to some of Schwitzgebel's examples seem unavailable in response to the examples above. For example, in at least some of Schwitzgebel's cases, one may contend that the unreliability that he attributes to introspection may instead be attributed to difficulties in categorizing and describing current conscious experience. For example, Schwitzgebel argues that introspection fails to reveal the character of one's current emotional experience; in response, however, it may be claimed that emotional experience is nuanced in a way that is not easily expressed in natural language. In this case, the problem is not with introspection, but rather with articulating the knowledge that introspection delivers. In contrast, especially in the examples concerning overall resemblance, the apparent inability of introspection to deliver a confident verdict does not seem, in any obvious way, to turn on difficulties in describing current conscious experience. The problem is not that there is introspective knowledge that is difficult to articulate; the problem is that introspection seems to provide no such knowledge in a wide range of cases.

Before moving on, it is worth briefly considering the relation between the present rejection of Super Justification for introspective resemblance judgments and a recent criticism of Revelation 
premised on the metaphysical basis for resemblance relations among phenomenal properties. Specifically, Antonin Broi (forthcoming) argues that the most plausible accounts of the metaphysical ground for resemblance relations among phenomenal properties are in fact inconsistent with Revelation, the idea that the essence of phenomenal properties is available to introspection. For example, on one such account, resemblance relations are grounded in partial identity, as one might claim that phenomenal orange resembles phenomenal red in virtue of including red as a constituent. The problem, however, is that introspectively attending to such properties does not seem to reveal any such internal structure; introspectively, phenomenal orange does not seem to be composed of phenomenal red and phenomenal yellow as constituents or parts. There is much that could be said about Broi's discussion, and I have only sketched the kind of considerations that he puts forward. But what I would like to mark is that the present challenge to Super Justification about introspective resemblance judgments takes a much different form. Specifically, my focus is on introspection itself and what knowledge it delivers when it comes to resemblance relations among phenomenal properties, quite independently of how one wishes to work out the nature of either resemblance in general or resemblance relations among phenomenal properties. I am, as it were, specifically interested in the "phenomenology". My claim is that when focusing on the phenomenology, Super Justification just does not seem plausible for an array of introspective resemblance judgments about current experience.

\section{Physicalism and Weak Super Justification}

It might be claimed that even if Strong Super Justification fails, Revelation is nonetheless needed to explain Weak Super Justification. However, I doubt that this is the case. Indeed, Goff would seem to agree with me on this point.

First, when Goff claims that there can be no physicalist explanation of Super Justification, he clearly has in mind Strong Super Justification. As above, the problem is specifically that the quotational account of phenomenal concepts cannot explain the Super Justificatory status of introspective 
resemblance judgments. However, again, it is doubtful that introspective resemblance judgments are Super Justified.

Second, Goff concedes that the quotational account of phenomenal concepts can explain Weak Super Justification. As above, the account can deal with judgments of the form "I am having an experience like that" and why we should be rationally confident in these judgments. I think that he is correct: one can explain why my judgment that I am having an experience like that is better justified than my perceptual judgment that there are two beers on the table in front of me by supposing that the experience itself is a constituent in my very judgment that I have am having an experience like that.

Revelation is not only not needed to explain Weak Super Justification. In fact, it comports poorly with this thesis. The reason is that if Revelation is true, this would seem to predict that it is Strong, not Weak Super Justification that holds. If Revelation is true, one would expect that quite generally the epistemic status of introspective judgments about current conscious experience is superior to ordinary perceptual judgments. One would expect, for example, that introspective resemblance judgments are in general in an epistemically better position than ordinary perceptual judgments and perhaps are epistemically akin to basic mathematical judgments. However, according to Weak Super Justification, this is not the case. Generally, given the failure of Strong Super Justification, we should be suspicious of any thesis according to which introspection quite generally reveals the nature of current conscious experience, which is just what Revelation asserts. Without something like Strong Super Justification, we should expect an explanation of the limited epistemic superiority of introspection to be more modest. This is what the quotational account of phenomenal concepts provides - it gives a principled based for why certain introspective judgments about current experience should have an especially strong epistemic status, without supposing that most or all such judgments have such a status. In effect, Revelation predicts that we should be in a better epistemic position with respect to current conscious experience than we in fact are. 


\section{Conclusion}

I have not claimed that phenomenal concepts are non-transparent or "opaque", that we do not know the nature of our conscious states when we think about them in terms of how they feel. I have argued, however, that this is a nonobvious thesis and that at least one argument for this thesis falls short. My discussions also suggest that when putting forward theses like Phenomenal Transparency, Revelation, and Super Justification, one should consider an array of different types of experiences. These are general theses, and if true, they should be supported by examples other than well-worn appeals to pain or simple resemblance judgments about visual experience. Finally, my arguments can be viewed as offering a limited defense of physicalism, given that the success of anti-physicalist arguments turns on our epistemic position with respect to the nature of consciousness.

\section{References}

Broi, A. Forthcoming. Revelation and Phenomenal Relations. The Philosophical Quarterly.

Chalmers, D. 1996. The Conscious Mind. New York: Oxford University Press.

Chalmers, D. 2009. The Two-Dimensional Argument Against Materialism. In B. McLaughlin (ed.), The Oxford Handbook on the Philosophy of Mind. Oxford: Oxford University Press.

Cowling, S. 2017. Resemblance. Philosophy Compass 12: 1-11.

Frankish, K. 2016. Illusionism as a Theory of Consciousness. Journal of Consciousness Studies 23: 11-39.

Goff, P. 2017. Consciousness and Fundamental Reality. Oxford: Oxford University Press.

Hill, C. 2009. Consciousness. Cambridge: Cambridge University Press.

Jackson, F. 1982. Epiphenomenal Qualia. Philosophical Quarterly 32: 127-36.

Jackson, F. 1986. What Mary Didn’t Know. Journal of Philosophy 83: 291-95.

McLaughlin, B. 2001. In Defense of New Wave Materialism: A Response to Horgan and Tienson. In C. Gillett and B. Loewer (eds), Physicalism and Its Discontents. Cambridge: Cambridge University Press.

Morreau, M. 2010. It Simply Does Not Add Up: Trouble with Overall Similarity. Journal of Philosophy 107: 469-90.

Papineau, D. 2002. Thinking about Consciousness. Oxford: Oxford University Press. 
Pereboom, D. 2011. Consciousness and the Prospects of Physicalism. New York: Oxford University Press.

Schwitzgebel, E. 2008. The Unreliability of Naïve Introspection. The Philosophical Review 117: 24573. 